properties, but the strategic planning process reportedly resulted in the creation of nearly 50 possible solutions, including legal challenges to the introduction of generic competitors. By the measure of influence on the market erosion curve of omeprazole, the investment in strategic planning was successful, as evidenced by the absence of generic omeprazole one year after the expiration of the patent on omeprazole. (The omeprazole patent expired in April 2001 but was extended to October 2001 by the conduct of a clinical study in pediatric patients.) The generic introduction of the first proton pump inhibitor (PPI) in the United States is much anticipated by pharmacy benefit managers, and the effects of the patent lawsuits are acutely obvious to managed care pharmacists. The legal challenges developed by the manufacturer of omeprazole began in 1985, 4 years before the drug was launched in the United States. ${ }^{17}$ Such legal challenges may not delay generic competition but have the minimum effect of ensuring that, when the patent lawsuits are resolved by the courts, one generic manufacturer has market exclusivity for the first 6 months. A 1984 federal law stipulates that a generic manufacturer that is challenged by a brand manufacturer in court is permitted 6 months of market exclusivity for the generic drug once the patent challenges are resolved. ${ }^{18}$

Managed care pharmacists might be interested in some of the legal arguments made in the course of the 17-year history of patent challenges regarding omeprazole. For example, a patent complaint was filed by the manufacturer for the use of omeprazole in combination with antibiotics for the eradication of Helicobacter pylori. The argument was that physicians could not prescribe omeprazole in combination with the use of antibiotics for heartburn because this practice would violate the patent. ${ }^{17}$ A patent dispute in New York commenced in December 2001, and the trial was concluded in June 2002. Four months later, on October 11, 2002, the U.S. District Court ruled that 3 of the 4 generic manufacturers had infringed on patents related to the subcoating formulation for omeprazole. ${ }^{19}$ The court found that the fourth generic manufacturer had its own patented method for a subcoating formulation for generic omeprazole, and this manufacturer had FDA approval to market its generic omeprazole, but this was not the generic company that held the original abbreviated new-drug application and the 6 months of market exclusivity for generic omeprazole. Therefore, the U.S. District Court decision in October 2002 made the date for the introduction of generic omeprazole in the U.S. market uncertain. ${ }^{20}$ Every day that the legal dispute continued earned another \$10 million in omeprazole sales.

\section{Direct-to-Patient Advertising (DTPA) and Direct-to- Consumer Advertising (DTCA) of Prescription Drugs}

A publishing company in St. Louis reported in mid-2002 that 17,000 community pharmacies were participating in "direct-topatient-advertising" (DTPA) in 2002 compared to just 3,000 3 years earlier. ${ }^{21}$ The pharmacy chains that contracted with the company in 2002 included some of the largest chain drug stores in the United States. The practice of DTPA involves generation of a patient-specific "health newsletter" that is based primarily on the drug prescribed but is customized to the patient name, age, gender, and whether the patient has drug insurance coverage. While the fine print in the health newsletters identifies the drug company sponsor, this practice could undermine the ability of the pharmacist to provide unbiased counseling to patients. For the drug companies, the practice permits marketing messages to be wrapped in the patient-pharmacist interaction. Marketing promotions in the "health newsletters" sometimes included recommendations for patients using low-cost generic drugs to switch to higher-cost sustained-release versions of the same drugs. In other cases, these patient-specific newsletters targeted users of a competing company's drug, urging patients to switch to the drug manufactured by the drug company that sponsored production of the newsletter. One billion such DTPA newsletters were expected to be produced in pharmacies in 2002, sponsored by 18 of the 20 largest U.S. drug companies, each paying as much as $\$ 10 \mathrm{M}$ to produce the health newsletters.

Eighteen months after the publication of federal rules that relaxed direct-to-consumer advertising (DTCA) of prescription drugs, IMS Health reported there were 40 brand-prescription drugs being advertised on television and about 100 brand drugs advertised to consumers in print and other media. ${ }^{22}$ TV advertisements accounted for $\$ 825 \mathrm{M}$ ( $55 \%$ of the total $\$ 1.5$ billion) compared to $\$ 686$ million for consumer-targeted print advertising. In this issue of the Journal, Glasgow, Schommer, Gupta, and Pierson report case-specific results of DTCA that support the results of consumer surveys. ${ }^{23}$ At least 5 consumer surveys conducted from 1998 through the first-half of 2002 have found a remarkably high reported rate of success in converting DTCA of prescription drugs into prescriptions written by physicians. By a measure that we might call the ad-to-Rx (ATR) ratio, DTCA of prescription drugs is very effective at generating new prescriptions. The ATR ratio ranges from $9 \%$ to $24 \%$, with a modal value of about $15 \%$.

An early study in 1998 found that 28\% of the elderly who saw a drug advertised on television spoke to their physician about the drug, and 33\% received a prescription for the requested drug, an ATR ratio of $9 \% .{ }^{24}$ A telephone survey of 1,205 adults of all ages conducted in the first half of 1999 found that $81 \%$ of respondents had seen, read, or heard an ad for a prescription drug (versus 63\% in late 1997), 28\% of those who had seen, read, or heard an ad asked their physician for the advertised drug, and an amazing $84 \%$ who reported asking their physician for the drug claimed to have received the requested drug, an ATR ratio of $24 \% .{ }^{25}$ A survey of 1,093 persons conducted in 2001 found that $32 \%$ of respondents had talked to their physician about an advertised drug, 26\% had actually requested a prescription for the advertised drugs, and $71 \%$ reported receiving the requested drug, an ATR ratio of 
about $18 \% .{ }^{26} \mathrm{~A}$ particularly well-designed survey of 2,511 persons conducted in late 2001 found that DTCA television ads caused $30 \%$ of the respondents to ask their physician about the advertised drug, 29\% actually asked for a prescription, and $44 \%$ received the prescription, an ATR ratio of $13 \% .{ }^{27}$ A telephone survey of 943 adults in early 2002 found that $69 \%$ of the respondents who had asked their physician for a specific brandname drug had received the drug, 5\% said that a DTC advertisement had precipitated the physician visit, and 4\% said they visited the physician because they wanted to obtain the advertised drug. ${ }^{28}$

From a quality-of-care perspective, DTCA might have other effects. Among the aforementioned studies, about one third of respondents who had asked their physicians about a particular drug reported that they did not know the disease condition of the advertised and requested drug. Among 1,300 AARP members surveyed in May 2000, one third did not notice the small print in DTC advertisements regarding the side effects and risks of drugs. ${ }^{29}$ A survey of 1,601 persons conducted by Prevention magazine in September and October 2001 found that 49\% believed that DTC drug advertising contributed to tension between physicians and patients. ${ }^{30}$ In the aforementioned survey of 2,511 persons sponsored by the Kaiser Family Foundation, 25\% of the viewers of the television advertisement for montelukast believed, erroneously, that the tablet could be used to alleviate an acute exacerbation of asthma, and $70 \%$ of participants in the survey indicated that they learned little or nothing from watching the advertisements. ${ }^{31}$

\section{Measuring Outcomes of 3-Tier Copay Drug Benefit Plans}

The dramatic increase in drug benefit costs in the period beginning in 1998 and continuing through 2002 caused a very rapid uptake of the 3- and 4-tier copay drug benefit plan designs among private health benefit plans, including Medicare+Choice plans. Languishing among 2-tier copay and closed formulary drug plans for 6 to 7 years, ${ }^{32}$ health plans, PBMs, and employers embraced these multi-tier copay plans with new vigor in 1999 and thereafter. But are these "new" drug benefit designs healthful for consumers and for the U.S. health care system? To begin to answer these questions, we first need a common nomenclature to use in defining these plans.

Single copay plans were used early in the administration of third-party prescription drug plans because the price (allowable charge in third-party payer vernacular) was not known. In the period before 1980, electronic claims processing of prescription claims and the precision and accuracy that we have come to expect today did not exist. The adoption of electronic processing for prescription drug claims in the early 1980s and its widespread implementation after 1985 permitted reconsideration of member cost-share in plan design. By the end of the 1980s, 2-tier copay plans were common, and percentage cost-share drug plans were feasible and even practical. Today, there exists a dizzying array of drug benefit designs among health plans and self-insured employers. Specified dollar copayments are overlaid with coinsurance, sometimes with deductibles or benefit (dollar) maximums. There are 3-, 4-, and even 5-tier plans. Research on the effects of these plans on cost, utilization, member satisfaction, and medication adherence, as well as other outcomes, demands that we have a nomenclature to define drug benefit plan design. Terms such as "multi-tier" or "3-tier" are not sufficiently specific to permit effective communication among managed care pharmacists and interested parties. For example, a 3-tier copay design may have 2 copay amounts (tiers) for brand formulary drugs while another 3-tier copay design may have only one copay amount (tier) for formulary drugs (i.e., nonformulary drugs would be assigned to the thirdcopay tier). Most 3-, 4-, and 5-tier copay designs assign the lowest (tier-1) copay to generic drugs, but even this is not always true.

Thus far, there have been few reliable results produced from efforts to measure clinical, service (humanistic), or cost outcomes of the multi-tier-copay drug plan designs. ${ }^{33}$ In this issue of the Journal, Nair, Ganther, Valuck et al., report that 3-tier drug plan members had less favorable attitudes toward their plans compared to those in 2-tier plans. ${ }^{34}$ This work advances our inspection of the effects of 3-tier copay drug benefit plans versus 2-tier plans, but the results should be interpreted cautiously and the discussion evaluated critically. While the authors attempted to measure the effects of age as an independent variable, their study groups were dramatically different. The 2-tier copay group $(\mathrm{N}=2,316)$ had $11.7 \%$ of its members over age 65 versus $54.7 \%$ for the 3-tier copay group $(\mathrm{N}=1,499)$. Not surprisingly, higher out-of-pocket copayment costs are incurred by persons over age 65 due to higher prescription utilization. Also, only $10 \%$ of the tier- 2 plan members were enrolled in Medicare+Choice versus $61.4 \%$ of the tier-3 plan members. All Medicare+Choice members had a $\$ 1,000$ annual benefit maximum, a variable that would be expected to affect member attitudes, particularly for the members with chronic diseases that were the subjects in their study.

Managed care strives to obtain the same or better outcomes at lower cost, thereby creating the ability to restrain the absolute amount and relative increase in health care premiums. Lower premiums make care affordable to more persons. Higher premiums make insurance coverage affordable to fewer persons..$^{35}$ A significant increase in the cost of health care and health care coverage in 2002 and 2003 can be expected to result in an increase in the number of uninsured. U.S. Census Bureau figures, released September 30, 2002, showed that the nation's uninsured population grew $3.5 \%$ in 2001, from 39.8 million in 2000 to 41.2 million. ${ }^{36}$ Free health care would make rationing necessary. Cost sharing at the point of care reduces the cost of health care premiums and can be employed in multi-tier copayments to influence member choice of care (e.g., drug). Therefore, multi-tier copay plans represent quintessential managed care, maximum choice. It is unfortunate, but reparable, 